\title{
Prevalence of experiences of domestic violence among psychiatric patients: systematic review
}

S. Oram, ${ }^{*}$ K. Trevillion, ${ }^{*}$ G. Feder and L. M. Howard

\section{Background}

Domestic violence has been linked with many mental disorders, including anxiety, depression, post-traumatic stress disorder, eating disorders and psychosis.

\section{Aims}

To estimate the prevalence (adult lifetime and past year) of different types of domestic violence experienced by men and women receiving psychiatric treatment.

\section{Method}

In a systematic review, a search of 18 electronic databases was supplemented by hand searching, citation tracking and updating a recent systematic review of criminal victimisation in psychiatric populations. Two reviewers independently extracted data and appraised study quality.

\section{Results}

Forty-two studies were included. The median prevalence of lifetime partner violence reported in high-quality papers was 30\% (interquartile range (IQR) 26-39) among female in-patients and 33\% (IQR 21-53) among female out-patients. Among male patients, one high-quality study reported a lifetime prevalence of $32 \%$ across mixed psychiatric settings. No study included a control group.

\section{Conclusions}

Psychiatric patients experience a high prevalence of domestic violence but there is limited information on family (non-partner) domestic violence, the prevalence of emotional abuse and the extent of risk compared with non-psychiatric controls.

\section{Declaration of interest}

G.F. and L.M.H. are members of the World Health Organization Guideline Development Group on Policy and Practice Guidelines for Responding to Violence Against Women and the National Institute for Health and Clinical Excellence/Social Care Institute for Excellence Guideline Development Group on Preventing and Reducing Domestic Violence.
Domestic violence is a major public health issue and has been linked with many mental health problems including anxiety, depression, post-traumatic stress disorder, eating disorders and psychosis. ${ }^{1-5}$ Prospective studies have shown that psychiatric disorder can increase vulnerability to domestic violence, and that domestic violence is associated with both risk and chronicity of mental disorder. ${ }^{6,7}$ A systematic review of domestic violence prevalence studies noted that when comparing the mean lifetime prevalence across various healthcare settings, studies conducted in psychiatric clinics and obstetrics and gynaecology clinics recorded the highest prevalence of physical violence (30-50\%) and sexual violence $(30-35 \%)$, whereas the highest mean lifetime prevalence of psychological violence was reported by studies conducted in psychiatric clinics and emergency departments $(65-87 \%){ }^{8}$ Other reviews have also suggested a high prevalence of being a victim of domestic violence among psychiatric patients. ${ }^{9,10}$ Howard et al, for example, reported that the lifetime prevalence of severe domestic violence ranged from 30\% to $60 \%$ among people receiving psychiatric in-patient treatment. ${ }^{10}$ However, these reviews did not critically appraise the quality of primary research. Moreover, previous reviews have largely neglected men's experiences of domestic violence, despite evidence of increased risk of victimisation among men with severe mental illness, ${ }^{11,12}$ and have given only limited consideration to broader research on the violent victimisation of psychiatric patients from which data on domestic violence could potentially be extracted. This systematic review therefore aimed to estimate, first, the prevalence (adult lifetime and past year) of being a victim of domestic violence among male and female psychiatric patients, and second, the risk of domestic violence among male and female psychiatric patients compared with controls.

*Joint first authors.

\section{Method}

\section{Selection criteria}

Studies were eligible for inclusion if they included male or female psychiatric patients who were 16 years or older; presented the results of peer-reviewed research based on experimental studies (e.g. randomised controlled trials, non-randomised controlled trials, parallel group studies), before and after studies, interrupted time series studies, cohort studies, case-control studies or crosssectional studies; and measured the prevalence or risk of adult lifetime and/or past year domestic violence, or collected data from which these statistics could be calculated. Mental health services were defined as secondary or tertiary care specialist services (in-patient, out-patient or community-based) providing psychiatric care and support to people with mental disorders. Domestic violence was defined as 'any incident of threatening behaviour, violence or abuse (psychological, physical, sexual, financial or emotional) between adults who are or have been intimate partners or family members regardless of gender or sexuality. ${ }^{13}$ When the review identified multiple eligible papers from the same study only the main paper reporting the largest number of participants with data of relevance to the objectives of the review was included.

\section{Search strategy}

Our search strategy followed Meta-analysis of Observational Studies in Epidemiology (MOOSE) guidelines. ${ }^{14}$ The protocol for this review was registered with the PROSPERO international database of prospectively registered systematic reviews in health and social care (www.crd.york.ac.uk/prospero), registration number CRD42011001281. Eighteen bibliographic databases were searched from date of inception to 31 March 2011 using a combination of Medical Subject Headings (MeSH) and text words 
(see Appendix 1 for a list of the databases used). Terms for domestic violence were adapted from published Cochrane protocols and previous literature reviews. ${ }^{9,15,16}$ No language restriction was used and potentially eligible papers were translated and assessments conducted using the English translated versions. The search strategy used for the Medline, EMBASE and PsycINFO databases is shown in online Appendix DS1. These searches were supplemented by citation tracking, hand searches, re-examining and updating an earlier review of victimisation among psychiatric populations, ${ }^{17}$ and expert recommendations.

\section{Study selection and data extraction}

Two reviewers (K.T. and S.O.) screened the downloaded titles and abstracts against the inclusion criteria; references were taken forward to the next stage of screening if it was unclear whether they met the inclusion criteria. The same two reviewers then assessed the full text of potentially eligible studies in terms of the inclusion criteria. If it was considered that studies had collected data on the prevalence and odds of domestic violence but had not presented it, authors were contacted for further information. Data on study design, sample characteristics, measurement of domestic violence and outcomes were extracted by the two reviewers from the included papers and entered in an electronic database. The outcomes of interest for the review were the prevalence and odds of adulthood lifetime and past year domestic violence among psychiatric patients. Where possible, outcome measures were extracted separately by gender, mental health setting and type and severity of violence.

\section{Quality appraisal}

The quality of included studies was independently appraised by two reviewers (K.T. and S.O.) using criteria adapted from validated tools. ${ }^{18-20}$ The reviewers compared scores and resolved any disagreements before calculating a final appraisal score. The quality appraisal checklist is shown in online Appendix DS2 and includes items to assess study design, the representativeness of study samples, the criteria used to measure domestic violence and the methods of statistical analysis. Scores for overall study quality and for questions relevant to selection bias and measurement bias are reported for all studies (see online Table DS1). High-quality papers were defined as those scoring $50 \%$ or above on questions assessing selection bias.

\section{Statistical analysis}

Information about the study design, study sample and the definition and measurement of domestic violence was summarised. Prevalence estimates (adult lifetime or past year) of domestic violence were calculated separately by gender and psychiatric setting when appropriate data were available. Odds ratios were not calculated because primary studies did not include control groups.

\section{Results}

The study selection process is presented in Fig. 1. Our literature search yielded 29707 unique references, of which 28584 references were excluded following title and abstract screening. Of the 1123 references that met - or potentially met - the inclusion criteria, 59 (56 dissertations and 3 journal articles) could not be located. Thus, 1064 full papers were retrieved and assessed. Forty-two papers were included in the review (online Table DS1) and 1022 were excluded. Of the 42 included papers, 32 were identified from

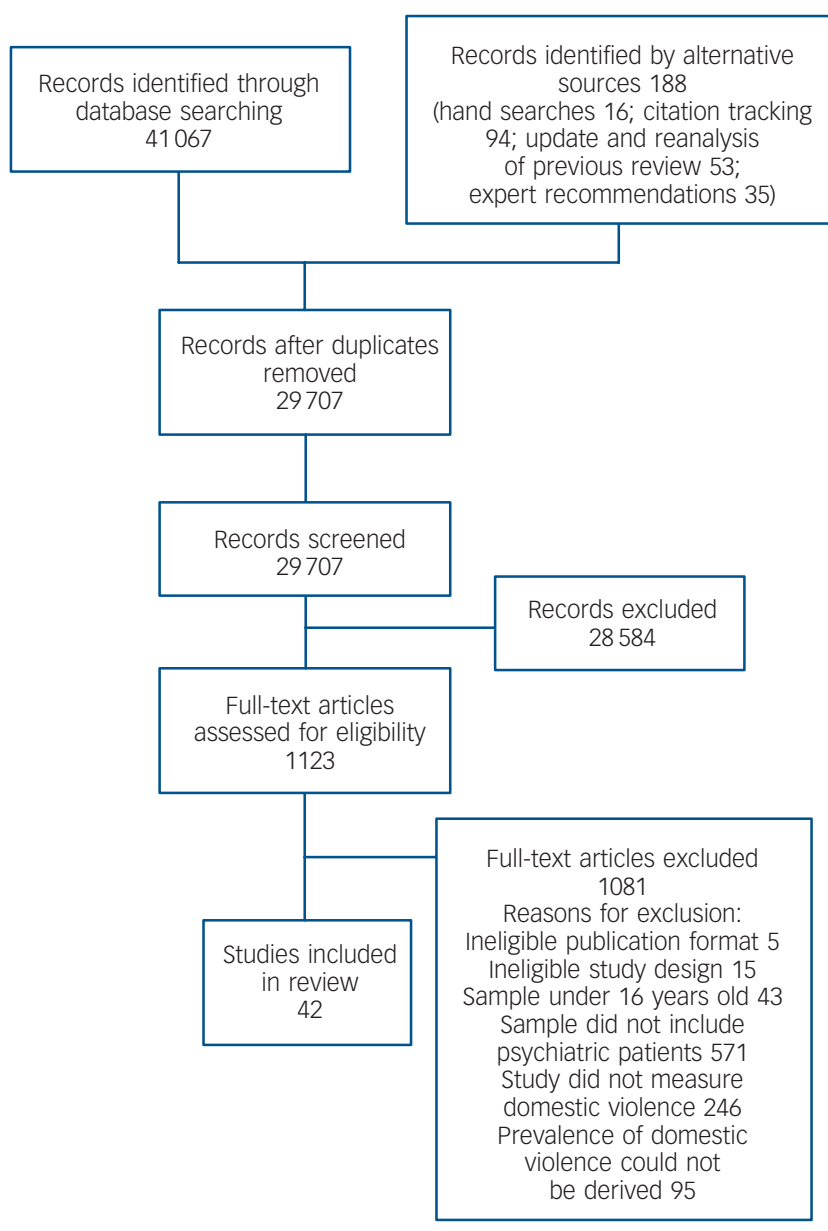

Fig. 1 Study selection.

searches of electronic databases, 7 from citation tracking, 1 from hand searching and 2 from expert recommendations. Only 1 of the 42 included papers was published in a language other than English. We excluded 10 non-English language papers after screening full-text translations, most often because they did not measure domestic violence and instead reported on general victimisation.

\section{Key features of included papers}

Of the 42 papers that examined the prevalence of domestic violence among psychiatric patients, 36 reported on domestic violence perpetrated by an intimate partner only (including 7 papers in which the definition was limited to violence perpetrated by a spouse) and 6 reported on violence perpetrated by either an intimate partner or other family member. Thirty-two studies measured lifetime experiences of domestic violence only, 7 past year domestic violence only and 3 both lifetime and past year experiences of domestic violence. Further details about the instruments used to assess domestic violence and the methods of data collection are provided for each study in online Table DS1.

Regarding study participants, 13 studies included either psychiatric in-patients only or presented data separately for this group, ${ }^{21-33} 16$ studies presented data for psychiatric out-patient samples, ${ }^{22,28,34-47}$ and 4 studies presented data for patients attending emergency psychiatric departments. ${ }^{48-51}$ Seven studies were conducted across a range of psychiatric settings and did not provide data disaggregated by service type..$^{51-57}$ In 5 papers it was not clear from which type of psychiatric service participants 
were recruited. ${ }^{58-62}$ Twenty-seven studies were conducted with women-only samples; one study was conducted with an all-male sample; 14 studies included both male and female participants but only 9 provided gender-disaggregated data on domestic violence.

\section{Psychiatric in-patient samples \\ Partner violence}

Adult lifetime violence. The prevalence of any adult lifetime partner violence among psychiatric in-patients ranged from 16\% to $94 \%$ among women and from $18 \%$ to $48 \%$ among men (see online Table DS1). Excluding studies that scored below 50\% on quality appraisal questions relating to selection bias, the median prevalence of lifetime partner violence was 30\% (interquartile range (IQR) 26-39, range 26-56) among women. ${ }^{21-23,29}$ No high-quality paper was identified that reported on lifetime partner violence among male psychiatric in-patients. Findings for specific types of partner violence were as follows:

(a) Physical violence: seven studies reported on the lifetime prevalence of physical partner violence among psychiatric in-patients. ${ }^{21,22,28-31,33}$ Among high-quality papers the median prevalence for female in-patients was 26\% (IQR 2641 , range $26-56) .^{21,22,29-31}$ One poor-quality paper presented data for men and reported a lifetime prevalence of $18 \% .^{30}$

(b) Sexual violence: one study reported a specific count on the lifetime prevalence of sexual partner violence, which was $16 \%$ among female in-patients; this paper scored below 50\% on quality appraisal questions relating to selection bias. ${ }^{25}$

(c) Psychological violence: one study reported a specific count on the lifetime prevalence of psychological partner violence, which was $94 \%$ among female in-patients; this paper scored below $50 \%$ on quality appraisal questions relating to selection bias. $^{31}$

Past year violence. Past year prevalence of physical partner violence ranged in three studies from $33 \%$ to $93 \% ;^{24,26,32}$ none of these studies scored $50 \%$ or more on selection bias. One highquality paper reported that the prevalence of past year physical violence among female psychiatric in-patients was $18 \%$, but this estimate combined violence from partners and family members. ${ }^{28}$

\section{Family violence}

Adult lifetime violence. Two studies reported on the prevalence of adult lifetime family violence among women. ${ }^{21,25}$ In the only high-quality study, lifetime prevalence of physical violence among female in-patients was estimated at $9 \%$ for violence perpetrated by a father and $6 \%$ for violence by a brother. ${ }^{21}$

Past year violence. One study of male and female psychiatric in-patients reported the prevalence of past year violence by a family member to be $46 \%$; this paper scored below $50 \%$ for

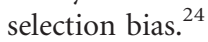

\section{Psychiatric out-patient samples}

Partner violence

Adult lifetime violence. The prevalence of any adult lifetime partner violence among out-patients ranged from $7 \%$ to $81 \%$ among women and from $2 \%$ to $6 \%$ among men (online Table DS1). Excluding studies that scored below $50 \%$ for selection bias, the median prevalence was $33 \%$ (IQR 21-53, range 15-81) among women..$^{22,38,40,42}$ No high-quality paper was identified that reported on domestic violence among men in this group. Findings for specific types of violence were:

(a) Physical violence: ten studies assessed lifetime physical partner violence among women out-patients and reported prevalence rates of $8-80 \%,{ }^{22,28,37-43,47}$ and two studies reported prevalence estimates of $2 \%$ and $6 \%$ among male out-patients. ${ }^{41,46}$ Among high-quality papers the median prevalence in female out-patients was $43 \%$ (IQR 25-51, range 8-60). ${ }^{22,40,42}$

(b) Sexual violence: estimates of the lifetime prevalence of sexual violence among women in the out-patient group were highly variable. ${ }^{37,39,40,43}$ In the only high-quality study the prevalence for women was $3 \%{ }^{40}$

(c) Psychological violence: lifetime prevalence of psychological violence among women out-patients ranged in three studies from $9 \%$ to $72 \% .^{40,41,43}$ Prevalence in the only high-quality study was $9 \% .{ }^{40}$

Past year partner violence. Fewer data were available on past year domestic violence. Two high-quality studies assessed past year physical abuse among female out-patients: one reported a prevalence of $16 \%$ for physical partner violence, ${ }^{42}$ the other reported a prevalence of $11 \%$ but combined data for violence from partners and family members. ${ }^{28}$

\section{Family violence}

Past year family violence. Bengtsson-Tops et al reported that $4 \%$ of a mixed sample of male and female psychiatric out-patients had been abused in the past year by a family member; however, this study scored below $50 \%$ on quality appraisal questions relating to selection bias. ${ }^{34}$

\section{Psychiatric emergency department samples}

\section{Partner violence}

Adult lifetime violence. The prevalence of adult lifetime domestic violence ranged from $42 \%$ to $60 \%$ among women attending psychiatric emergency departments and was estimated at $8 \%$ among men attenders (see online Table DS1). Only one paper scored $50 \%$ or over on selection bias: this study estimated that the prevalence among women was $60 \% .{ }^{50}$ No high-quality paper was identified that reported on domestic violence among men attenders.

Past year violence. One high-quality study assessed past year experiences of partner violence among women attending psychiatric emergency departments and reported the prevalence rates of past year physical and sexual violence to be $20 \%$ and $16 \%$ respectively. ${ }^{50}$

\section{Mixed psychiatric settings}

\section{Partner violence}

Adult lifetime violence. Seven studies collected data across a range of psychiatric settings (e.g. in-patient, out-patient, community, emergency and forensic mental health services) and did not disaggregate their results according to setting (online Table DS1). Excluding studies that scored below $50 \%$ on quality appraisal questions relating to selection bias, the median prevalence of lifetime partner violence among men and women patients was $26 \%$ (IQR 20-44, range 26-63). ${ }^{52,53,57}$ Two highquality papers also reported gender-specific prevalence estimates. The first, a large Swedish cross-sectional study that attempted to question all adult women using psychiatric in-patient and 
out-patient services over a 1-week period about their experiences of violence, additionally estimated that $26 \%$ women had ever experienced violence from a current partner and $23 \%$ from a previous partner. ${ }^{52}$ The second, conducted in the USA, estimated that $63 \%$ of female psychiatric patients had ever experienced partner violence (including 50\% physical violence and 32\% sexual violence). ${ }^{53}$ The latter study also estimated that $32 \%$ of male psychiatric patients had experienced partner violence (including $18 \%$ physical violence and $4 \%$ sexual violence).

\section{Family violence}

One high-quality paper reported that, among patients in mixed psychiatric settings, the prevalence of adult lifetime violence by a family member was $11 \% .^{52}$

\section{Discussion}

The review findings suggest a high prevalence of experiences of domestic violence among psychiatric patients. Among female patients, being a victim of lifetime partner violence was reported by about a third of in-patients and out-patients. ${ }^{21-23,29,38,40,42}$ Only one high-quality paper reported the prevalence of being a victim of domestic violence among male patients: Chang et al surveyed patients across a range of psychiatric settings and estimated that $18 \%$ had experienced lifetime physical partner violence and $4 \%$ had experienced lifetime sexual partner violence. ${ }^{53}$ The review identified only six studies on the prevalence of violence perpetrated by family members, of which only two were of high quality: these two studies reported that $11 \%$ of a mixed sample of male and female psychiatric out-patients reported family violence, ${ }^{52}$ and that $9 \%$ and $6 \%$ of female in-patients reported adult lifetime physical violence by a father or brother respectively. ${ }^{21}$

No study included non-psychiatric controls representative of the general population. Thus, although most of the reviewed studies reported higher estimates of the prevalence of domestic violence than have been reported for general population samples, ${ }^{63,64}$ quantifying the extent to which psychiatric populations are at greater risk of domestic violence remains difficult.

\section{Strengths and limitations}

The review employed a comprehensive search strategy following MOOSE guidelines. ${ }^{14}$ We identified a number of methodological and conceptual issues in the primary studies that weaken the estimates of prevalence. Half of the included studies were judged to score poorly on questions relating to selection bias. We found that most studies used non-probability sampling and did not provide information on the representativeness of their samples, the potential impact of non-participation, or study power. Furthermore, few studies reported detailed exclusion criteria or provided information about participants' primary diagnoses. We have therefore carried out a further systematic review to examine the prevalence and risk of domestic violence in people with specific psychiatric disorders using different sources of data (PROSPERO database registration number CRD42011001241 (yet to be published)). The most rigorous study that we identified in this review, which attempted to survey all women attending psychiatric in-patient and out-patient services over a 1-week period about their experiences of domestic violence, reported that a quarter had experienced abuse from their current partner. ${ }^{52}$ The exclusion, however, of individuals who were not able to give informed consent means that the findings cannot be generalised to the most severely ill patients.
The reliability and comparability of primary studies were also limited by the methods of data collection and instruments used to assess domestic violence. Data collection methods varied between studies and included researcher-administered questionnaires during face-to-face interviews, self-completed questionnaires and case file reviews. Face-to-face interviews were used in more than half of the included studies but may contribute to the underdetection of violence: a randomised controlled trial of methods of screening for domestic violence in various healthcare settings found that women preferred the use of self-completed questionnaires over face-to-face interviews when the same questionnaires were used. ${ }^{65}$ Case file reviews are also likely to underestimate the prevalence of domestic violence experienced by psychiatric patients: the underdetection and poor recording of domestic violence, even where routine enquiry has been implemented, is well documented. ${ }^{10,42,65,66}$ Future studies should consider using self-completed questionnaires to assess domestic violence.

Studies also varied with regard to the instruments used to measure domestic violence. Among studies that employed a validated instrument to detect domestic violence, the most commonly used tool was the Conflict Tactics Scale (CTS). ${ }^{67,68}$ However, authors frequently reported that they made modifications to this and other instruments without describing how, if at all, the adapted instruments had been validated. The reliability and comparability of study findings are likely to have been reduced by this practice. In addition, although the CTS is one of the most widely used measures of violence, it has been criticised for its measurement of acts out of context (i.e. it does not make it clear whether acts of violence were in attack or in defence), its gender neutrality and its failure to measure other forms of partner violence, ${ }^{69}$ although sexual violence has been partly addressed in the revised version. ${ }^{68}$

In 11 papers, authors reported having developed their own measures to assess domestic violence, and in a further 10 no details were provided about the instrument used to assess violence. Moreover, several studies did not enquire specifically about domestic violence but instead asked participants about their general experiences of violence. We included those studies in our review if they reported the identity of the perpetrator and the age at which abuse occurred. Studies thus differed with regard to which forms of violence and specific behaviours were enquired about, which contributed to the observed variation in the prevalence of victimisation.

\section{Implications of findings}

Our review highlights the high prevalence of domestic violence among people using a range of psychiatric services. It also, however, draws attention to the lack of high-quality evidence on domestic violence among psychiatric populations and to the absence of research comparing psychiatric patients' risk of domestic violence with that of other clinical populations or the general population. Further evidence gaps are also apparent. First, despite evidence that emotional abuse is strongly associated with poor health outcomes, ${ }^{70,71}$ few studies collected data on psychiatric patients' experiences of psychological violence. Second, few studies included violence from family members within their definition of domestic violence. The prevalence of victimisation by family members in the few studies in which it was measured, however, suggests that family-perpetrated domestic violence may be an issue of relevance for some psychiatric patients, as it is for the general population: in 2010-2011, a fifth (22\%) of all homicides in London were domestic-related, with the murder of a parent by a son being the most prevalent. ${ }^{72}$ Finally, and despite evidence that suggests that men with severe mental illness 
are at increased risk of violent victimisation, ${ }^{11,12}$ few studies collected data on the prevalence of domestic violence in male patients. Professionals who work with psychiatric patients across a range of settings should be aware of the high prevalence of victimisation among men and women in this group and be able to identify violence and respond appropriately to their patients' needs.

S. Oram, PhD, K. Trevillion, BSc, Section of Women's Mental Health, Institute of Psychiatry, King's College London; G. Feder, MD, FRCGP, School of Social and Community Medicine, Academic Unit of Primary Health Care, University of Bristol; L. M. Howard, PhD, MRCPsych, Section of Women's Mental Health, Institute of Psychiatry, King's College London, UK

Correspondence: Louise M. Howard, Section of Women's Mental Health, Institute of Psychiatry, King's College London, PO31, David Goldberg Centre, De Crespigny Park, Denmark Hill, London SE5 8AF, UK. Email: louise.howard@kcl.ac.uk

First received 2 Feb 2012, final revision 19 Jul 2012, accepted 20 Aug 2012

\section{Funding}

This paper presents independent research commissioned by the National Institute for Health Research (NIHR) under its Programme Grants for Applied Research scheme (RP-PG-0108-10084). The authors are all supported by the NIHR Programme Grants for Applied Research scheme (RP-PG-0108-10084). L.M.H. is also supported by the NIHR South London and Maudsley National Health Service Foundation Trust Biomedical Research Centre - Mental Health.

\section{Acknowledgements}

We thank the experts in this area who responded so helpfully in our request for data. We also gratefully acknowledge Fraser Anderson for her assistance during the summer of 2011, Mauricio Moreno for technical support and Seynam Kluvitse for administrative assistance. We are also grateful to Michael Dewey, Monika Janosik, Leo Koeser, Sharron Leung, Kazuyo Machiyama, Mauricio Moreno, Oliver Schauman and Tracy Teng for translating articles that were published in non-English languages.

\section{Appendix 1}

\section{Electronic databases searched for systematic review}

Biomedical databases

Academic Search Complete, British Nursing Index, CINAHL, Cochrane, EMBASE, Health Management Information Consortium (HMIC), Medline, Maternity and Infant Care, PsycINFO, Science Direct, Web of Science (including Science Citation Index, Social Sciences Citation Index, Arts \& Humanities Citation Index, and Conference Proceedings Citation Index for Science and for Social Science and Humanities)

\section{Social sciences databases}

Applied Social Sciences Index and Abstracts, International Bibliography of the Social Sciences, JSTOR, Sociological Abstracts

\section{Theses and dissertations}

DART-Europe E Theses Portal, Electronic Theses Online Service (EThOS), Networked Digital Library of Theses and Dissertations

\section{References}

1 Campbell JC. Health consequences of intimate partner violence. Lancet 2002; 359: 1331-6.

2 Flach $C$, Leese $M$, Heron J, Evans J, Feder G, Sharp D, et al. Antenatal domestic violence, maternal mental health and subsequent child behaviour: a cohort study. BJOG 2011; 118: 1383-91.

3 Golding MJ. Intimate partner violence as a risk factor for mental disorders: a meta-analysis. J Fam Violence 1999; 14: 99-132.

4 Danielson KK, Moffitt TE, Caspi A, Silva PA. Comorbidity between abuse of an adult and DSM-III-R mental disorders: evidence from an epidemiological study. Am J Psychiatry 1988; 155: 131-3.
5 Ludermir A, Lewis G, Valongueiro S. Violence against women by their intimate partner during pregnancy and postnatal depression: a prospective cohort study. Lancet 2010; 376: 903-10.

6 Brown GW, Harris TO, Hepworth C, Robinson R. Clinical and psychosocial origins of chronic depressive episodes. II. A patient enquiry. Br J Psychiatry 1994; 165: 457-65.

7 Ehrensaft MK, Moffitt TE, Caspi A. Is domestic violence followed by an increased risk of psychiatric disorders among women but not among men? A longitudinal cohort study. Am J Psychiatry 2006; 163: 885-92.

8 Alhabib S, Nur U, Jones R. Domestic violence against women: systematic review of prevalence studies. J Fam Violence 2010; 25: 369-82.

9 Friedman SH, Loue S. Incidence and prevalence of intimate partner violence by and against women with severe mental illness. J Womens Health 2007; 16: $471-80$.

10 Howard LM, Trevillion K, Khalifeh H, Woodall A, Agnew-Davies R, Feder G. Domestic violence and severe psychiatric disorders: prevalence and interventions. Psychol Med 2010; 40: 881-93.

11 Goodman LA, Salyers MP, Mueser KT, Rosenberg DS, Swartz M, Essock MS, et al. Recent victimization in women and men with severe mental illness: prevalence and correlates. J Trauma Stress 2001; 14: 615-32.

12 Teplin LA, McClelland GM, Abram KM, Weiner DA. Crime victimization in adults with severe mental illness - comparison with the national crime victimization survey. Arch Gen Psychiatry 2005; 62: 911-21.

13 Home Office. Domestic Violence: A National Report: 7. UK Home Office, 2005.

14 Stroup DF, Berlin JA, Morton SC, Olkin I, Williamson GD, Rennie D, et al Meta-analysis of observational studies in epidemiology: a proposal for reporting. Meta-analysis Of Observational Studies in Epidemiology (MOOSE) group. JAMA 2000; 283: 2008-12.

15 Smedslund G, Dalsbø TK, Steiro AK, Winsvold A, Clench-Aas J. Cognitive behavioural therapy for men who physically abuse their female partner. Cochrane Database Syst Rev 2007; 3: CD006048.

16 Ramsay J, Richardson J, Carter YH, Davidson LL, Feder G. Should health professionals screen for domestic violence? Systematic review. BMJ 2002; 325: 1-13.

17 Maniglio R. Severe mental illness and criminal victimization: a systematic review. Acta Psychiatr Scand 2009; 119: 180-91.

18 Loney PL, Chambers LW. Critical appraisal of the health research literature: prevalence or incidence of a health problem. Chronic Dis Canada 2000; 19 $170-7$.

19 Downs SH, Black $\mathrm{N}$. The feasibility of creating a checklist for the assessment of the methodological quality both of randomised and non-randomised studies of health care interventions. J Epidemiol Community Health 1998; 52: 377-84.

20 CASP UK. Critical Appraisal Skills Programme (CASP). Available at: http:// www.casp-uk.net.

21 Bryer BJ, Nelson AB, Miller BJ, Krol AP. Childhood sexual and physical abuse as factors in adult psychiatric illness. Am J Psychiatry 1987; 144: 1426-30.

22 Carlile JB. Spouse assault on mentally disordered wives. Can J Psychiatry 1991; 36: 265-9.

23 Carmen E, Rieker PP, Mills T. Victims of violence and psychiatric illness. Am J Psychiatry 1984; 141: 378-83.

24 Cascardi M, Mueser KT, DeGiralomo J, Murrin M. Physical aggression against psychiatric inpatients by family members and partners. Psychiatr Serv 1996; 47: 531-3.

25 Chandra PS, Deepthivarma S, Carey MP, Carey KB, Shalinianant MP. A cry from the darkness: women with severe mental illness in India reveal their experiences with sexual coercion. Psychiatry Interpers Biol Process 2003; 66 $323-34$

26 Heru AM, Stuart GL, Rainey S, Eyre J, Recupero PR. Prevalence and severity of intimate partner violence and associations with family functioning and alcohol abuse in psychiatric inpatients with suicidal intent. J Clin Psychiatry 2006; 67: 23-9.

27 Hoffman BF, Toner B. The prevalence of spousal abuse in psychiatric in-patients: a preliminary study. Can J Commun Ment Health 1988; 7: 53-60.

28 Hudson Scholle S, Rost MK, Golding MJ. Physical abuse among depressed women. J Gen Intern Med 1998; 13: 607-13.

29 Husain A, Anasseril DE, Harris PW. A study of young-age and mid-life homicidal women admitted to a psychiatric hospital for pre-trial evaluation Can J Psychiatry 1983; 28: 109-13.

30 Post RD, Willett AB, Franks RD, House RM, Back SM, Weissberg MP, et al. A preliminary report on the prevalence of domestic violence among psychiatric inpatients. Am J Psychiatry 1980; 137: 974-5.

31 Sansone RA, Chu J, Wiederman M. Self-inflicted bodily harm among victims of intimate-partner violence. Clin Psychol Psychother 2007; 14: 352-7. 
32 Weizmann-Henelius G, Viemero V, Eronen M. Psychological risk markers in violent female behavior. Int J Forens Ment Health 2004; 3: 185-96.

33 Zanarini MC, Frankenburg FR, Reich DB, Marino MF, Haynes MC, Gunderson JG. Violence in the lives of adult borderline patients. J Nerv Ment Dis 1999; 187: 65-71.

34 Bengtsson-Tops A, Ehliasson K. Victimization in individuals suffering from psychosis: a Swedish cross-sectional study. J Psychiatr Ment Health Nurs 2012; 19: 23-30.

35 Ford JD. Ethnoracial minority background, psychological trauma, PTSD, and DESNOS among urban low-income women with severe mental illness. J Psychol Trauma 2008; 7: 170-84.

36 Friedman SH, Loue S, Goldman Heaphy EL, Mendez N. Intimate partner violence victimization and perpetration by Puerto Rican women with severe mental illnesses. Community Ment Health J 2011; 47: 156-63.

37 Goodman LA, Dutton MA, Harris M. Physical and sexual assault prevalence among episodically homeless women with serious mental illness. Am J Orthopsychiatry 1995; 65: 468-78.

38 Herman JL. Histories of violence in an outpatient population: an exploratory study. Am J Orthopsychiatry 1986; 56: 137-41.

39 Johnston-McCabe $P$, Levi-Minzi M, Hasselt V, Vanderbeek A. Domestic violence and social support in a clinical sample of deaf and hard of hearing women. J Fam Violence 2011; 26: 63-9.

40 Leithner K, Assem-Hilger E, Naderer A, Umek W, Springer-Kremser M. Physical, sexual, and psychological violence in a gynaecologicalpsychosomatic outpatient sample: prevalence and implications for mental health. Eur J Obstet Gynec Reprod Biol 2009; 144: 168-72.

41 Lipschitz DS, Kaplan ML, Sorkenn JB, Faedda GL, Chorney P, Asnis GM. Prevalence and characteristics of physical and sexual abuse among psychiatric outpatients. Psychiatr Serv 1996; 47: 189-91.

42 Morgan JF, Zolese G, McNulty J, Gebhardt S. Domestic violence among female psychiatric patients: cross-sectional survey. Psychiatrist 2010; 34 461-4.

43 Ramanathan S. Violence against women. Int Med J 1996; 3: 145-8.

44 Surrey J, Swett C, Michaels A, Levin S. Reported history of physical and sexual abuse and severity of symptomatology in women psychiatric outpatients. Am J Orthopsychiatry 1990; 60: 412-7.

45 Swett C, Cohen C, Surrey J, Compaine A, Chavez R. High rates of alcohol use and history of physical and sexual abuse among women outpatients. Am J Drug Alcohol Abuse 1991; 17: 49-60.

46 Swett C, Surrey J, Cohen C. Sexual and physical abuse histories and psychiatric symptoms among male psychiatric outpatients. Am J Psychiatry 1990; 147: 632-6.

47 Vahip I, Doğanavşargil O. Domestic violence and female patients [in Turkish] Turk Psikiyatri Derg 2006; 17: 107-14.

48 Briere J, Woo R, McRae B, Foltz J, Sitzman R. Lifetime victimization history, demographics, and clinical status in female psychiatric emergency room patients. J Nerv Ment Dis 1997; 185: 95-101.

49 Currier GW, Briere J. Trauma orientation and detection of violence histories in the psychiatric emergency service. J Nerv Ment Dis 2000; 188: 622-4.

50 Owens KR. Patient-centered provider behaviors and disclosure of intimate partner violence in a psychiatric emergency setting. PhD Thesis, University of Pittsburgh, 2007.

51 Paranjape A, Heron S, Kaslow NJ. Utilization of services by abused, low-income African-American women. J Gen Intern Med 2006; 21: 189-92.
52 Bengtsson-Tops A, Markstrom U, Lewin B. The prevalence of abuse in Swedish female psychiatric users, the perpetrators and places where abuse occurred. Nord J Psychiatry 2005; 59: 504-10.

53 Chang JC, Cluss PA, Burke JG, Hawker L, Dado D, Goldstrohm S, et al. Partner violence screening in mental health. Gen Hosp Psychiatry 2011; 33: 58-65.

54 Dienemann J, Boyle E, Baker D, Resnick W, Wiederhorn N, Campbell J. Intimate partner abuse among women diagnosed with depression. Issues Ment Health Nurs 2000; 21: 499-513.

55 Ferreira da Silva L. A man's right to beat his wife - marital violence in Portuguese society [in Portuguese]. Analise Social 1991; 26: 385-97.

56 McPherson DM, Delva J, Cranford AJ. A longitudinal investigation of intimate partner violence among mothers with mental illness. Psychiatr Serv 2007; 58: 675-80.

57 Yellowlees PM, Kaushik AV. An examination of the associations between life problems and psychiatric disorders in a rural patient population. Austr $\mathrm{N} Z \mathrm{~J}$ Psychiatry 1994; 28: 50-7.

58 Brown A, Cosgrave E, Killackey E, Purcell R, Buckby J, Yung AR. The longitudinal association of adolescent dating violence with psychiatric disorders and functioning. J Interpers violence 2009; 24: 1964-79.

59 Osgood NJ, Manetta AA. Abuse and suicidal issues in older women. Omega (Westport) 2000; 42: 71-81.

60 Tham S, Ford T, Wilkinson D. A survey of domestic violence and other forms of abuse. J Ment Health 1995; 4: 317-21.

61 Waller G. Sexual abuse as a factor in eating disorders. Br J Psychiatry 1991; 159: 664-71.

62 Weingourt R. Wife rape in a sample of psychiatric patients. Image J Nurs Sch 1990; 22: 144-7.

63 Tjaden P, Thoennes N. Extent, Nature, and Consequences of Intimate Partner Violence. US Department of Justice, 2000

64 Walby S, Allen J. Domestic Violence, Sexual Assault and Stalking: Findings From The British Crime Survey. UK Home Office, 2004.

65 MacMillan LH, Wathen CN, Jamieson E, Boyle M, MCNutt AL, Worster A, et al. Approaches to screening for intimate partner violence in health care settings: a randomized trial. JAMA 2006; 296: 530-6.

66 Steiner-Craine L, Henson EC, Colliver AJ, MacLean GD. Prevalence of a history of sexual abuse among female psychiatric patients in a state hospital system. Hosp Community Psychiatry 1988; 39: 300-4.

67 Straus MA. Measuring intrafamily conflict and violence: the conflict tactics scales. J Marriage Fam 1979; 41: 75-88.

68 Straus MA, Hamby LS, Boney-McCoy S, Sugarman BD. The Revised Conflict Tactics Scales (CTS2) development and preliminary psychometric data. J Fam Issues 1996; 17: 283-316.

69 Loseke DR, Kurz D. Men's violence toward women is the serious social problem. In Current Controversies On Family Violence, 2nd edn (eds DR Loseke, RJ Gelles, MM Cavanaugh): 79-96. Sage, 2005.

70 Garcia-Moreno C. Intimate-partner violence and fetal loss. Lancet 2009; 373: 278-9.

71 Pico-Alfonso MA. Psychological intimate partner violence: the major predictor of posttraumatic stress disorder in abused women. Neurosc Biobehav Rev 2005; 29: 181-93.

72 Metropolitan Police Authority. Domestic and Sexual Violence Board Final Report 2006-2011. Metropolitan Police Authority, 2011 (http:// policeauthority.org/Metropolitan/downloads/work/dsvb/110713-02.pdf). 